\title{
O IMPACTO DAS PRÁTICAS DE GESTÃO DE PESSOAS SOBRE A MOTIVAÇÃO DO COLABORADOR EM ORGANIZAÇÕES DA SOCIEDADE CIVIL DE INTERESSE PÚBLICO (OSCIPS )
}

\author{
André Salata Lima ${ }^{1}$ \\ Cleiciele Albuquerque Augusto ${ }^{2}$
}

LIMA, A. S.; AUGUSTO, C. A. O impacto das práticas de gestão de pessoas sobre a motivação do claborador em organizações da sociedade civil de interesse público (OSCIPS). Rev. Ciênc. Empres. UNIPAR, Umuarama, v. 19, n. 1, p. 17-40, jan./jun. 2018.

RESUMO: O presente estudo objetiva compreender a influência que as práticas de gestão de pessoas exercem sobre a motivação no trabalho realizado por colaboradores em Organizações da Sociedade Civil de Interesse Público (OSCIPs) de Maringá-PR. A busca por essa compreensão considera as necessidades básicas de cada indivíduo, fatores de higiene, fatores motivacionais e incentivos de interação social pelos quais funcionários são motivados. Para tanto, a partir de estudos referentes aos processos de gestão de pessoas, motivação e terceiro setor, com foco para organizações qualificadas como OSCIP, foram realizadas entrevistas semiestruturadas com gestores dessas instituições, bem como aplicados questionários com os seus funcionários. Os resultados indicaram que as organizações apresentam práticas de gestão de pessoas pouco estruturadas, com processos não formalizados e ausência de planejamento estratégico para os recursos humanos. Constatou-se que os colaboradores possuem uma forte orientação para causas sociais, o que estabelece uma sólida ligação emocional entre o funcionário e a organização. Conclui-se que, apesar de necessidades de estima e realização terem sido destacadas pelos funcionários, tais necessidades não foram observadas como fatores motivadores significativos.

PALAVRAS-CHAVE: Gestão Social; Motivação; ONGs; Processos de Gestão de Pessoas.

\section{THE IMPACT OF PEOPLE MANAGEMENT PRACTICES ON EMPLOYEE MOTIVATION IN PUBLIC INTEREST NON- GOVERNMENTAL ORGANIZATION (CSOPI)}

\begin{abstract}
This study aims at understanding the influence of Human Resource Management on the motivation of the work developed by employees in $\mathrm{Pu}$ -

DOI: 10.25110/receu.v19i1.6432

${ }^{1}$ Graduação em Administração - Trainee em Auditoria da KPMG

${ }^{2}$ Doutora em Administração - Professora Adjunta da Universidade Estadual de Maringá
\end{abstract}


blic Interest Non-Governmental Organizations (CSOPI) in the city of Maringá, Brazil. It considers the basic needs of each individual, hygiene and motivational factors, as well as social interaction incentives. Therefore, semi-structured interviews were held with Human Resource managers based on studies related to Human Resource Management, motivation and third sector, focusing on organizations qualified as public interest non-governmental organizations. The results indicated that the organizations presented people management practices with little structure, non-formalized processes and a lack of strategic human resources planning. It could be observed that the employees are strongly focused on social causes, which establishes a solid emotional connection between the employee and the organization. Although the employees had highlighted the need of esteem and self-accomplishment, such needs have not been seen as significant motivating factors.

KEYWORDS: Human Resource Management Processes; Motivation; NGOs; Social Management.

\section{EL IMPACTO DE LAS PRÁCTICAS DE GESTIÓN DE PERSONAS SOBRE LA MOTIVACIÓN DEL COLABORADOR EN ORGANIZACIONES DE LA SOCIEDAD CIVIL DE INTERÉS PÚBLICO (OSCIPS)}

RESUMEN: El presente estudio tiene como objetivo comprender la influencia que las prácticas de gestión de personas ejercen sobre la motivación en el trabajo realizado por colaboradores en Organizações da Sociedade Civil de Interesse Público (OSCIPs) de Maringá. La búsqueda de esa comprensión considera las necesidades básicas de cada individuo, factores de higiene, factores motivacionales e incentivos de interacción social por los cuales los empleados son motivados. Para ello, a partir de estudios referentes a los procesos de gestión de personas, motivación y tercer sector, con foco para organizaciones calificadas como OSCIP, se realizaron entrevistas semiestructuradas con gestores de esas instituciones, así como aplicados cuestionarios con sus empleados. Los resultados indicaron que las organizaciones presentan prácticas de gestión de personas poco estructuradas, con procesos no formalizados y ausencia de planificación estratégica para los recursos humanos. Se constató que los colaboradores poseen una fuerte orientación hacia causas sociales, lo que establece un sólido vínculo emocional entre el funcionario y la organización. Se concluye que, a pesar de las necesidades de estima y realización, haber sido destacadas por los funcionarios, tales necesidades no se observaron como factores motivadores significativos.

PALABRAS CLAVE: Gestión Social; Motivación; ONGs; Procesos de Gestión de Personas. 


\section{INTRODUÇÃO}

O termo terceiro setor, traduzido do inglês "third sector", originalmente se associava, nos Estados Unidos, a Organizações Não Governamentais e ao voluntariado (FERNANDES, 1997). Devido à sua participação nas causas coletivas, o terceiro setor foi amplamente divulgado dentro do contexto de lutas pela redemocratização vivenciada pela América Latina e Leste Europeu durante períodos de políticas autoritárias, difundindo conceitos de cidadania e distinguindo-a do mercado por seu foco de atuação. Englobam-se nesse mesmo setor diversos tipos de empreendimentos sociais, como fundações, associações, cooperativas e demais organizações com viés social que não visam ao lucro (FERNANDES, 1997; TENÓRIO, 2009).

Dentro do terceiro setor, destacam-se as Organizações da Sociedade Civil de Interesse Público (OSCIP), compostas por pessoas jurídicas de direito privado sem fins lucrativos. São organizações em que os excedentes operacionais, dividendos, bonificações ou parcela do patrimônio não são distribuídos entre os associados ou envolvidos com a entidade e não sejam os usuários descritos no objetivo social da organização. Essa qualificação exclui outras organizações presentes no terceiro setor como sociedades comerciais, instituições religiosas, cooperativas, partidos políticos, escolas e hospitais privados não gratuitos (RO$\mathrm{ESCH}, 2002$ ).

Por um lado, observa-se que as características diferenciadas do trabalho no terceiro setor, e das OSCIPs de forma particular, podem representar fatores motivadores que geram a satisfação dos funcionários, como maior agilidade e flexibilidade, forte motivação pela ideologia e autonomia para realizar as atividades (PEREIRA, 2013). Por outro lado, por falta de conhecimento técnico ou falta de tempo, muitas vezes, os trabalhadores envolvidos em ONGs ocupam posições secundárias dentro das metas da organização, devido à forte priorização do público alvo para quem a ONG presta serviço, o que pode causar desmotivação com o trabalho (OLIVEIRA JUNIOR, 2007). Assim, evidenciam-se fatores esquecidos que podem gerar a insatisfação, conforme expõe Herzberg, (1974).

Segundo Maslow (1943), deve-se considerar que a motivação é composta por necessidades básicas hierarquizadas e não exclusivas umas às outras, de tal maneira que quando uma é parcialmente satisfeita, outra necessidade se manifesta. É responsabilidade do gestor, portanto, saber diferenciar e identificar os incentivos motivacionais associados a cada funcionário ou inerente a cada tarefa. Concomitantemente, McClelland (1972) classifica os fatores motivacionais referentes às interações sociais entre um indivíduo e o ambiente e três formas de incentivos: incentivos de realização, relacionados ao desafio pessoal de aumentar o desempenho ou realizar tarefas complexas com sucesso; incentivos de 
afiliação, onde o indivíduo prioriza o desenvolvimento de boas relações e por meio de cooperação mútua; incentivos de poder, caracterizados pelo interesse por controlar situações diversas e exercer influência. As motivações do indivíduo são restritas as experiências vivenciadas, de forma que cada pessoa tem um foco de incentivos diferentes e responde de maneira diferente aos estímulos externos.

Com base no exposto, o presente estudo objetiva compreender a influência da gestão de recursos humanos na motivação no trabalho realizado por colaboradores em OSCIPs de Maringá. Para tanto, buscou-se descrever as práticas de gestão empregadas pelos gestores no tratamento dos trabalhadores de OSCIPs na cidade de Maringá; evidenciar como se apresenta a motivação desses trabalhadores, considerando as necessidades básicas de cada indivíduo, fatores de higiene e motivacionais e incentivos de motivação por interação social; identificar o impacto das práticas de gestão quanto a motivação do colaborador.

Visando à transformação da sociedade, as universidades brasileiras têm um importante papel de análise nas mudanças apresentadas no sistema econômico, por meio do conceito de pesquisa, ensino e extensão. Até o início dos anos 90 ainda não haviam cursos voltados para estudos específicos e capacitação continuada de profissionais que buscavam desenvolvimento dentro do Terceiro Setor (PEREIRA, 2013). Conforme afirma Tenório (2009), deve-se considerar que os estudos de Administração Pública não englobam em sua total amplitude as peculiaridades das organizações do Terceiro Setor, bem como a Administração de Empresas, que limita sua visão a conceitos de eficiência, eficácia, qualidade e produtividade, não articulando conceitos de antropologia, comunicação, psicologia e sociologia. Ademais, apesar de se reconhecer a importância do gerenciamento de pessoas, pouco se sabe como as ONGs aplicam essa prática (ASSIS; VIEGAS; CKAGNAZAROFF, 2012). De igual forma, poucos são os estudos específicos confrontando a motivação de funcionários remunerados dentro do contexto das Organizações Não Governamentais (ROESCH, 2002).

Para atingir o objetivo proposto, além desta seção introdutória com a apresentação dos temas propostos, foi desenvolvida a revisão de literatura, com tópicos essenciais para o estudo, como processos de gestão de recursos humanos, sua realidade em organizações do terceiro setor e aspectos teóricos sobre motivação de pessoas. Posteriormente, apresentaram-se os procedimentos metodológicos da pesquisa, envolvendo informações sobre os tipos de dados coletados e os instrumentos de coleta e análise. Na sequência, analisaram-se dos dados, visando responder os objetivos propostos, e, por fim, realizaram-se as conclusões da pesquisa, seguidas das referências utilizadas. 


\section{METODOLOGIA}

No presente estudo, optou-se pela pesquisa de natureza qualitativa, devido a preocupação de se compreender o mundo empírico em seu ambiente natural, com posicionamento neutro perante os entrevistados. Rejeitou a análise numérica quantitativa, vista que se buscou um olhar holístico, não limitado apenas a um conjunto de variáveis. O estudo, por conseguinte, é considerado como descritivo, ao buscar compreender o quadro referencial dentro do qual os indivíduos interpretam seus pensamentos, sentidos e ações (GODOY, 1995).

Coletaram-se dados primários, ou seja, dados obtidos diretamente para a pesquisa, por meio de entrevistas semiestruturadas com gestores e trabalhadores de 5 OSCIPs localizadas em Maringá-PR: uma instituição de crédito, uma fundação responsável por fomentar cultura, uma instituição responsável por fomentar conhecimento político, um conselho municipal de segurança e um instituto responsável por fomentar cursos e treinamentos sobre comércio exterior.

Foi utilizado o método de análise interpretativa para análise dos dados coletados, a partir das categorias de análise identificadas na revisão da literatura, estabelecendo relação entre o conteúdo discutido e os resultados obtidos (SEVERINO, 2005), em um esforço de amadurecer o tema e contextualizar para a realidade dos colaboradores entrevistados. Esse racional analítico pode ser observado na Figura 4. O recorte de pesquisa é transversal, pois o estudo busca estabelecer relação entre a situação em um determinado momento histórico (BORDALO, 2006), no caso, no ano de 2016.

Figura 1: Esquema de análise e categorias de estudo
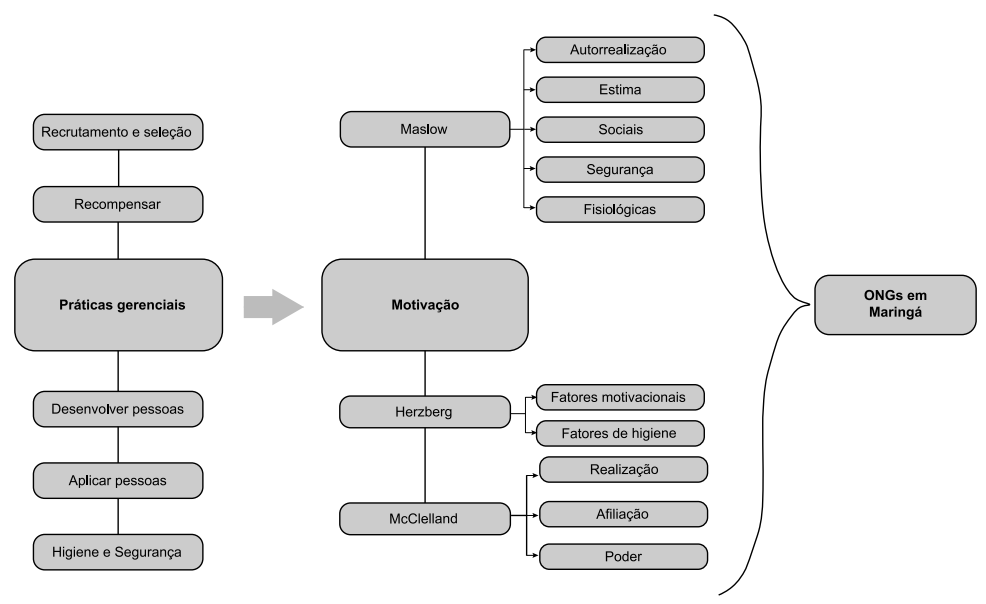

Fonte: Elaborado pelos autores, 2017 
Dentre as quarenta OSCIPs que constam no site do Ministério da Justiça Federal, vinte e seis se encontram inativas ou abdicaram da qualificação de OSCIP. Diante disso, cinco organizações participaram completamente da pesquisa por meio da entrevista com o gestor administrativo ou gestor de recursos humanos para analisar as práticas de gestão, e a aplicação do questionário de motivação com os funcionários dedicados integralmente a organização. Contou-se com a participação de cinco gestores de pessoas e quinze funcionários remunerados que trabalham integralmente entre as cinco organizações pesquisadas.

O roteiro de entrevista aplicado aos gestores contém oito questões abertas que buscaram esclarecer a maturidade do departamento de gestão de pessoas, considerando a maneira como são aplicados os cinco processos de gestão de pessoas, bem como a influência desses processos sobre a motivação dos funcionários. Já o questionário, aplicado aos funcionários, contou com dezenove questões fechadas e duas questões abertas. Buscou-se, assim, compreender a percepção do funcionário sobre como a OSCIP desempenha os processos capazes de gerar ou manter a motivação do funcionário, bem como identificar se esses processos realmente são vistos como motivadores pelos funcionários.

\section{REVISÃO DA LITERATURA}

\subsection{Processos de recursos humanos}

Fischer (1998) sugere que as funções atribuídas aos recursos humanos sejam modificadas como consequência de mudanças dentro e fora das empresas. Com isso, com as mudanças presentes na relação entre Estado, mercado e terceiro setor, torna-se importante adequar as novas necessidades dos gestores de recursos humanos e a forma como lidam com o funcionário.

Ao analisar os objetivos e pressupostos básicos de empresas na era industrial, Bohlander e Snell (2009) descrevem os recursos estratégicos limitados a obtenção de lucros, sendo o capital o principal recurso estratégico. Já nas empresas atuais, como destaca Robbins (2005) e Bohlander e Snell (2009), representantes da era da informação, o principal recurso estratégico é o conhecimento. Segundo esses autores, há apenas uma maneira da empresa ter acesso a esse bem: por meio do acesso das pessoas as quais tais recursos residem. Essa nova percepção torna o capital humano o bem mais precioso de uma organização.

De acordo com Messeder (1992), o gestor de recursos humanos deve harmonizar expectativas opostas. Por um lado, há a empresa ou Estado que buscam maior produtividade, redução de custos e aumento de lucros. Por outro lado, os empregados visam às melhorias nas condições de trabalho, aumento de salário, oportunidades de realização profissional, estabilidade, entre outros. De igual modo, Pinto (2013) enfatiza que a gestão de recursos humanos engloba todas as 
medidas e ações que interferem na relação entre a organização, representada pelo interesse dos proprietários, e o interesse dos empregados.

O planejamento pertinente a gestão de recursos humanos, por sua vez, pode ser dividido entre as ações relativas à: seleção, integração, formação, desenvolvimento, recompensa e relacionamento, que dizem respeito tanto ao nível coletivo como individualmente (PINTO, 2013). Marras (2002) descreve como atividades principais de gestão de pessoas as atividades de atrair e selecionar, recompensar, desenvolver e aplicar pessoas, além de providenciar a higiene e segurança do trabalho.

Recrutamento consiste no processo pelo qual a empresa divulga e oferece a vaga ao mercado, no caso de uma contratação externa, ou aos funcionários, por meio de promoções ou transferências, em caso de contratações internas. Procura-se, desta forma, candidatos que ocupem as vagas que suprirão as demandas previamente identificadas na empresa (MARRAS, 2002), uma vez que os candidatos estão em contato com a vaga. Identifica-se o mais qualificado entre aqueles recrutados, mediante o processo de seleção. Marras (2002) destaca que o processo deve envolver uma metodologia para garantir que o candidato selecionado seja o mais próximo de suprir as necessidades da empresa. Para isso, a empresa pode utilizar, segundo Bohlander e Snell (2009), métodos individuais, como inscrições, entrevistas, testes de capacidade, psicológicos ou de personalidade, validação de referências, até métodos para avaliar o relacionamento interpessoal, por meio de dinâmicas de grupos.

Os processos de recompensar os funcionários envolvem diversos fatores. Segundo Robbins (2005), além da remuneração básica, tem-se programas de incentivos, vinculados ao alcance de metas e objetivos e, ainda, programas de benefícios, concedidos aos funcionários para melhorar a sua qualidade de vida e, consequentemente, a produtividade na organização. Dessa forma, como destaca Marras (2002) e Bohlander e Snell (2009), ao considerar a remuneração, deve-se somar a remuneração variável, gratificações e bônus, comissões, benefícios oferecidos e as horas-extras que serão pagas aos funcionários. A remuneração pode ser utilizada como uma ferramenta com o qual a empresa pode enriquecer a relação de troca entre interesses pessoais e os da organização, uma vez que a remuneração possibilita que o funcionário satisfaça algumas de suas necessidades pessoais. É também uma maneira de bonificar o comprometimento dos funcionários que exercem um bom trabalho e apresentam resultados a empresa (MARRAS, 2002).

Conforme Marras (2002), o processo de desenvolver pessoas pode corresponder a três objetivos específicos para a empresa: formação profissional, especialização e reciclagem. O primeiro visa a aumentar o grau ideal de capacidade do trabalhador para trabalhador, em que as práticas e o conhecimento necessário 
para exercer a função são transmitidos. Na especialização, pretende-se aprofundar em uma prática específica dentro de uma área de trabalho, para que os resultados sejam otimizados. Por fim, a prática de reciclagem revê conceitos e práticas de trabalho, atualizando-os quando necessário. Conforme a empresa busque despertar as potencialidades do funcionário, cria-se um espaço para crescimento profissional e organizacional (MARRAS, 2002).

Os processos de aplicar pessoas, por sua vez, são responsáveis por direcionar os recursos presentes na empresa, a fim de garantir uma boa e clara relação entre os trabalhadores. O desenho de cargos e divisão de responsabilidade, avaliação de desempenho são ferramentas aplicadas nesse processo para evitar conflitos e orientar a um clima favorável de interação (MARRAS, 2002; BOHLANDER; SNELL, 2009). Os métodos de avaliação de desempenho envolvem desde autoavaliação, avaliação pelo gerente e pela equipe de trabalho, até métodos mais modernos como a avaliação 360 graus e a Avaliação Participativa por Objetivos (APO). Nessas últimas, os objetivos são estabelecidos de forma consensual entre funcionários e seus gerentes e os funcionários têm maior autonomia e participação na sua avaliação (ROBBINS, 2005; BOHLANDER; SNELL, 2009).

Marras (2002) menciona que higiene e segurança correspondam a responsabilidade de atuar nas correções de etapas, desenvolver estudos e implementar ações para garantir a salubridade e segurança do trabalhador, caracterizadas por medidas técnicas, educacionais e psicológicas. Corresponde ao interesse da empresa em prevenir custos adicionais por acidentes e paralisação na produção, enquanto para o funcionário significa a busca de melhores condições de trabalho. (MARRAS, 2002).

\subsubsection{Práticas de gestão de pessoas em organizações do terceiro setor}

Ainda que seja conhecida a importância da gestão e sua capacidade direta de influenciar a organização, pouco se sabe a respeito de como ela é realizada nas organizações pertencentes ao terceiro setor (ASSIS; VIEGAS; CKAGNAZAROFF, 2012). A expectativa, porém, é de que as ONGs sejam gerenciadas por líderes idealistas e comprometidos com a causa social, bem como adotem processos participativos na tomada de decisão e operem em uma estrutura flexível (ROESCH, 2002).

Nesse contexto, Lewis (2001) descreve algumas barreiras encontradas no terceiro setor quanto à aplicação de uma gestão de recursos humanos efetiva. $\mathrm{O}$ autor destaca cinco principais razões: a) cultura organizacional orientada à ação; b) foco dos recursos direcionado aos que recebem assistência da ONG, subestimando a importância de financiar despesas administrativas indiretas; c) falsa crença de que ferramentas de gestão devem ser exclusivamente utilizadas 
por organizações do setor privado, ao se supor que o principal objetivo da gestão seja o de explorar, oprimir ou discriminar o funcionário; d) propensão em conservar estruturas pequenas e informais, a fim de lidar com aspectos gerenciais de forma reativa, apenas atendendo a demanda de necessidades conforme sejam identificadas; e) influência exercida por agências doadoras sob a gestão da ONG.

Considerando as características de trabalho dentro do primeiro, segundo e terceiro setor, pode-se diferenciar o segundo e o terceiro quanto à característica não lucrativa, o que também reflete o comportamento ideológico de quem trabalha em ONGs. Além do engajamento idealista presente nas organizações sem fins lucrativos, a idealização por lucros também se contrapõem à finalidade pública das ONGs (MELO, 2016). Em relação ao trabalho do terceiro setor em comparação com o primeiro, nota-se maior agilidade e independência por parte das ONGs em suas tarefas. Outra importante característica dentro do terceiro setor é que esse promove melhorias específicas de serviço de caráter não universal e proximidade com as bases que prestam serviço, uma vez que as ONGs não atendem à sociedade como um todo, diferente dos trabalhos desenvolvidos pelo Estado (LIMA NETO, 2013). As ONGs são organizações mais objetivas e focadas nos resultados, não nos procedimentos, como visto nas atividades do Estado. Em um contexto prático, isso reflete a diferença entre trabalhar diretamente com número e trabalhar diretamente com pessoas, como é o caso das ONGs (MELO, 2016; LIMA NETO, 2013).

A gestão social, objeto frequente de estudos e práticas relacionados à gestão de políticas sociais, como as exercidas pelas ONGs, chegou ao Brasil atrás do Programa de Estudos em Gestão Social (PEGS), por meio da Escola Brasileira de Administração Pública da Fundação Getúlio Vargas (TENÓRIO, 2006). Diferente da gestão estratégica, determinado a atender as necessidades do mercado, a gestão social visa à inclusão do indivíduo e a cooperação entre os agentes envolvidos. Com isso, constataram-se importantes diferenças entre as formas de gestão, com destaque para: fortes orientações ideológicas, informalidade da ação, muitas vezes caracterizando-as mais como movimentos sociais à organizações estruturada, e igualdade e participação democrática na gestão dos processos administrativos (DINIZ; MATTOS, 2002).

Em relação ao planejamento de atividades, as ONGs apresentam uma estrutura dinâmica e fragmentada. Trabalha-se com objetivos de curto prazo e desenvolvem-se projetos específicos para a necessidade momentânea da organização. Nota-se também a interferência que um processo tem sobre o outro, devido, principalmente, a estrutura enxuta (PEREIRA, 2013).

\subsection{Abordagem conceitual de motivação}

Segundo Bergamini (1994), a motivação é uma questão central na vida 
de qualquer indivíduo, pois envolve a força propulsora capaz de movê-lo no curso do que gera satisfação e evitar o que o insatisfaz. Esse estímulo, por sua vez, se expressa de maneira diferente para cada pessoa que o experimenta.

\subsubsection{Motivação segundo Maslow e Herzberg}

Maslow (1943), em sua obra "A Theory of Human Motivation", agrupou fatores motivacionais em cinco necessidades básicas diretamente relacionadas entre si, de forma hierárquica e não exclusivas. Assim, quando uma necessidade é razoavelmente suprida, a próxima necessidade virá à tona, o que faz com que sejam tanto parcialmente satisfeitas, quanto parcialmente insatisfeitas. Segundo o autor, as necessidades representam objetivos pelos quais os indivíduos buscam mover-se para suprir.

As cinco necessidades básicas definidas por Maslow são: a) as necessidades fisiológicas, relacionadas às necessidades biológicas mais fundamentais e primárias do ser humano, como o descanso e alimentação; b) as necessidades de segurança, associadas à estabilidade e condições seguras quando aplicado ao ambiente de trabalho; c) as necessidades sociais, que representam as necessidades de manter boas relações pessoais; d) as necessidades de estima, através do reconhecimento pessoal e do reconhecimento de outras pessoas; e) as necessidades de autorrealização, referentes ao crescimento do indivíduo (MASLOW, 1943).

Figura 2: Necessidades hierárquicas de Maslow
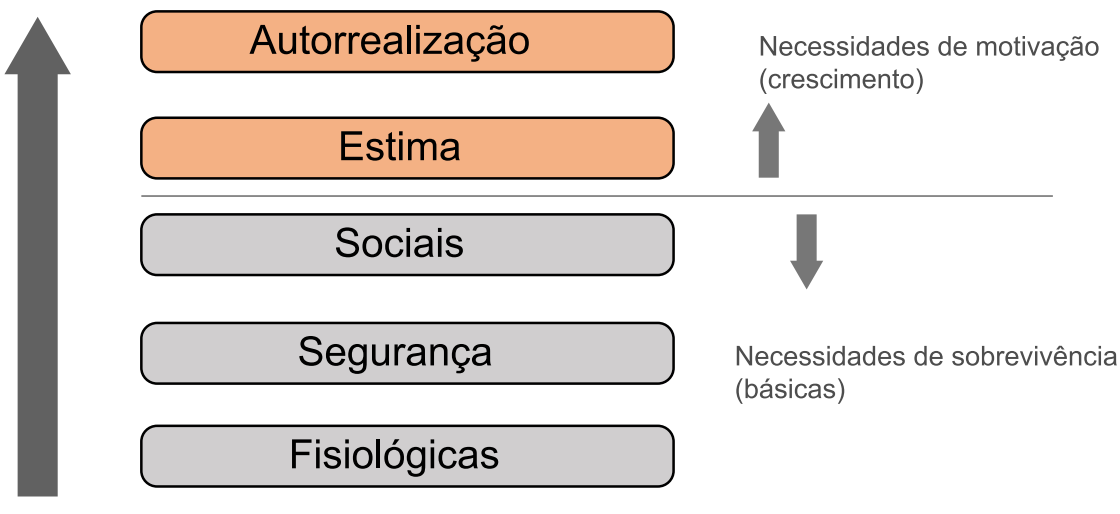

Fonte: Silva (2008, p. 211).

Segundo Maslow (1943), uma necessidade já saciada não é suficiente para gerar motivação a um indivíduo. Devido a isso, em uma sociedade segura, estável e onde as necessidades mais básicas da hierarquia são minimizadas, a necessidade para um indivíduo em particular tende a ser minimizada, negada ou até 
mesmo esquecida, como é o caso da fome para um indivíduo com condições de se alimentar constantemente. Para o autor, as necessidades consideradas, ainda que sejam fatores motivacionais determinantes, não predizem, exclusivamente, o comportamento usual de um indivíduo e devem ser associadas a outras teorias para explicar o processo gerador de motivação. Utilizando o mesmo exemplo da fome, a necessidade da fome por si só não induz o indivíduo a escolher entre um alimento ou outro (MASLOW, 1943).

Considerando a motivação dentro do contexto organizacional, Herzberg (1974) relaciona-a com a satisfação no trabalho. O autor sugere que a satisfação e insatisfação no ambiente de trabalho são oriundos de diferentes fatores, descritos como fatores de higiene, ligados diretamente à prevenção de desmotivação, e como fatores motivacionais, responsáveis pela satisfação do trabalhador e por criar atitudes positivas dentro da empresa.

Os fatores de higiene, ou extrínsecos, por si só não garantem a satisfação do funcionário, mas sua ausência leva à insatisfação. Caracterizam-se por estarem relacionados ao contexto da empresa e estrutura da organização, como as características de supervisão, política da empresa e administração, relacionamentos interpessoais no ambiente organizacional, condições de trabalho, status da empresa, segurança e salário. Os fatores de higiene não expõem as atividades exercidas pelo colaborador (HERZBERG, 1974).

Por sua vez, fatores motivacionais ou intrínsecos, descritos por Herzberg (1974), refletem os resultados de necessidade de crescimento dentro da empresa. Realização e reconhecimento do trabalho, atribuição de novas responsabilidades, oportunidade de crescimento e as próprias atividades executadas pelo trabalhador podem ser considerados fatores motivacionais. $\mathrm{O}$ papel efetivo do gestor, segundo o autor, não seria motivar os funcionários para atingirem suas tarefas, e sim proporcionar tarefas capazes de serem realizadas, a fim de motivá-lo. Uma empresa que busca aumentar a qualidade de vida do funcionário deve integrar ambos os conceitos e os distinguir entre frequência e importância. Todos os fatores higiênicos possuem igual importância nas devidas circunstâncias, enquanto que os fatores com maior grau de motivação, de maneira geral, ocorrem em menor frequência (HERZBERG, 1974, 1987). 
Figura 3: Teoria dos dois fatores de Herzbeg

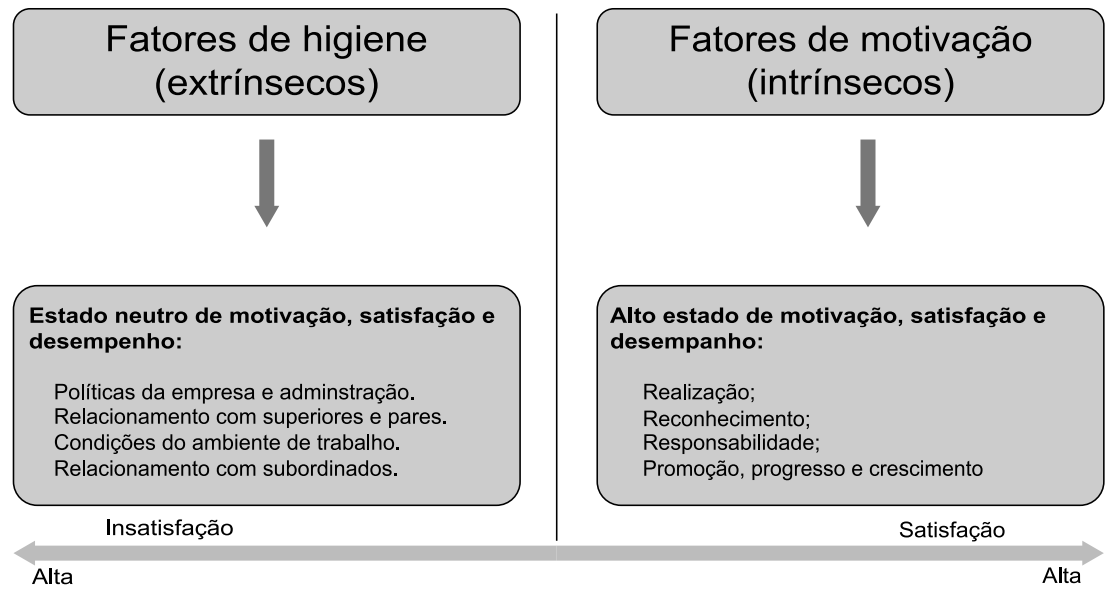

Fonte: Silva (2008, p. 214).

\subsubsection{Motivação segundo McClelland}

Seguindo a mesma vertente, McClelland $(1972,1973,1978)$ argumenta que a quantidade de incentivo de realização durante a execução de uma tarefa é inversamente proporcional à percepção da tarefa se concretizar. Dito de outra forma, quanto maior a dificuldade, maior será o incentivo para o sucesso ao se executar, variando a intensidade de acordo com a orientação motivacional de cada indivíduo.

Buscando despertar o motivo da realização em um grupo de pessoas e compreender os efeitos por trás do comportamento, McClelland propôs uma pesquisa de amostragem de pensamento espontâneo (MCCLELLAND, 1972, 1973). Identificou que as orientações motivacionais de um indivíduo podem ser distinguidas em três comportamentos de escolha, que correspondem às formas de interação social: incentivos de realização, afiliação e poder (MCCLELLAND, 1972).

O autor buscou captar, dentro das fantasias de uma pessoa, as reais considerações e preocupações interiores no momento analisado, com base em histórias que foram sugeridas por imagens ilustradas em uma tela por poucos segundos para dois grupos - o grupo teste e o grupo controle.

Previamente, o grupo teste foi informado que seriam submetidos a um questionário utilizado para identificar pessoas com elevada capacidade administrativa e que o resultado estava diretamente ligado a capacidade de inteligência dos mesmos. Com isso, o grupo amostrado tinha ciência de que seria avaliado em função de padrões de excelência como inteligência e capacidade de liderança. 
Esperava-se, portanto, que a maioria dos membros do grupo teste tivessem um maior envolvimento com o experimento realizado em relação ao grupo controle, que não recebeu instrução e nem realizou o questionário antes da coleta de amostragens.

Pode-se observar que o grupo que estava em condição de pressão apresentou maior número de referências quanto o alto desempenho e padrão de excelência. McClelland diferencia, com isso, o número de referências entre as três orientações já listadas, denominadas $\mathrm{N}$ de Realização, $\mathrm{N}$ de Afiliação e $\mathrm{N}$ de poder.

Pessoas com uma alta taxa do $\mathrm{N}$ de Realização foram identificados por destacar a excelência nas histórias que narraram. Essa orientação é particularmente adequada ao papel empresarial. Já o número de fatores relacionados à afiliação representam descrições obtidas mediante as histórias em que se destacaram fatores de interação social e revelam a natureza da relação. Identificou-se que pessoas motivadas por afiliação buscam instaurar, preservar ou reproduzir uma relação afetiva positiva com a sociedade em geral. Por fim, pessoas direcionadas a motivações de poder tendem a se preocupar com a capacidade de controlar uma circunstância e se caracterizam por se satisfazerem com situações de domínios emocionais, como a satisfação em vencer ou repúdio à perda.

Percebe-se, portanto, que os fatores motivacionais, descritos por Maslow (1943), descrevem os fatores motivacionais como incentivos constantes e nunca plenamente saciados. Além disso, classificou os fatores em uma hierarquia de necessidades, em que os fatores considerados mais primitivas e instintivas compõe a base da pirâmide, e as necessidades sociais se apresentam no topo das necessidades. Os fatores motivacionais de Herzberg $(1974,1987)$ associam-se a satisfação dentro do ambiente de trabalho e são divididos entre fatores motivacionais e fatores de higiene, capazes de motivar ou impedir a desmotivação de um indivíduo, respectivamente. Por fim, McClelland $(1972,1973,1978)$ descreve como incentivos sociais têm importâncias diferentes para cada indivíduo, dependendo do seu comportamento de escolha. Incentivos de realização, poder e afiliação também influenciaram nas escolhas individuais devido a propensão da pessoa em correr riscos para atingir seus objetivos. 
Figura 4: Comparação entre as teorias motivacionais de Herzberg, Maslow e McClelland.

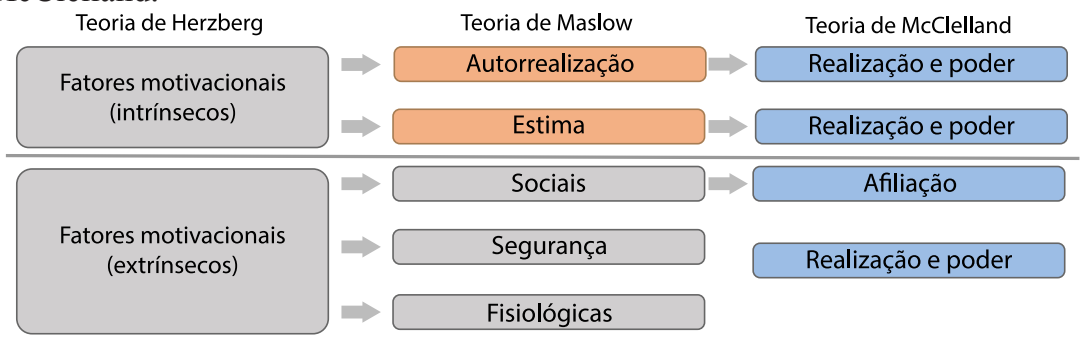

Fonte: Adaptado de Silva (2008, p. 220).

\section{RESULTADOS E DISCUSSÃO}

Para análise dos dados, descreveram-se a estrutura e práticas de gestão de pessoas, conforme os dados obtidos por meio do roteiro de entrevista aplicado com o próprio gestor e questionário aplicado com os funcionários. Descreveu-se neste tópico como são realizados os processos de atração e seleção, o de recompensar, desenvolver e aplicar pessoas e o processo de higiene e segurança. Posteriormente, analisou-se, por meio da percepção dos funcionários da OSCIP, como a organização trabalha com os fatores que podem causar ou manter a motivação dos funcionários, bem como compreender as principais causas de motivação dos entrevistados.

\subsection{Gestão de pessoas}

Conforme descrito por Pereira (2013), confirmou-se, pela realidade de Maringá, que as OSCIPs apresentam uma estrutura enxuta e nenhuma apresenta um departamento exclusivo de gestão de pessoas. Quase todas as organizações apresentaram uma estrutura com menos de três funcionários efetivados, o que torna inviável um departamento específico para gestão de pessoas. O responsável pela gestão, na maior parte dos casos, é o gerente operacional. Duas OSCIPs localizadas dentro da Associação Comercial e Empresarial de Maringá (ACIM) contam com uma estrutura externa de gestão de pessoas para as atividades específicas de elaboração de folha de pagamento e auxílio no processo de recrutamento e seleção. Todas as OSCIPs apresentam um conselho administrativo composto por voluntários, comprometidos a atuar no nível estratégico.

Relativo ao processo de atrair e selecionar, as organizações pesquisadas apresentam, em sua quase totalidade, um corpo de funcionários suficiente para atender a demanda de trabalho exigido pela OSCIP. Conforme descrito por Marras (2002), o processo de recrutamento envolve uma metodologia capaz de 
garantir que o candidato supra as necessidades identificadas na organização. Nos casos observados, identifica-se a necessidade de um novo funcionário através do crescimento sólido da demanda e sobrecarga dos atuais funcionários, de maneira que não há um planejamento estratégico dos Recursos Humanos. Dessa forma, há uma ação reativa e a posteriori das OSCIPs. Por outro lado, nenhuma organização apresentou crescimento de demanda ou do quadro de funcionários desde o momento de ingresso do gestor operacional entrevistado e, em algumas organizações estudadas, o corpo de funcionários reduziu desde 2015.

As vagas abertas, em casos de reposição de funcionários, foram preenchidas pela promoção de antigos colaboradores, ou seja, o recrutamento interno é preponderante. As contratações externas, em todos os casos, foram para os cargos mais básicos e, em algumas OSCIPs, o ingresso à organização ocorre inicialmente pelo regime de estágio, para que depois ocorra a efetivação. Nos casos de contratação externa, procuram-se candidatos que já possuam um relacionamento com a organização ou que sejam indicados por algum membro. O processo de seleção realizado em todas as organizações era composto apenas por entrevistas individuais entre o gestor e o candidato. Em consequência ao número reduzido de candidatos, o processo de seleção se torna mais simples e com menos fases.

Quanto ao processo de recompensar pessoas, devido ao caráter social e sem fins lucrativos e as próprias políticas para qualificação de OSCIPs, grande parte das organizações estudadas não possuem um sistema de recompensa vinculado ao desempenho. Nesses casos, observou-se que benefícios oferecidos são os propostos pela CLT, ou seja, benefícios legais, nos termos propostos por Robbins (2005), considerado como remuneração básica. Há também, segundo o autor, benefícios espontâneos, oferecidos pela empresa em busca de retenção de talentos e aumento de produtividade. Em um dos casos, pelo serviço da OSCIP estar relacionado à educação, os funcionários têm a oportunidade de realizarem cursos em diversas área, como treinamento de vendas, cursos de comércio exterior e gestão de projetos.

Nenhuma organização, exceto a instituição de crédito pesquisada, apresenta acompanhamento dos funcionários por meio de metas, o que também inviabiliza a remuneração variável, segundo os termos indicados por Marras (2002), ao relacionar bonificações com o resultado e comprometimento dos funcionários.

Já para o processo de desenvolver pessoas, considerando a realidade das OSCIPs de Maringá e os três objetivos específicos descritos por Marras (2002) ao se desenvolver pessoas, a formação profissional consiste nos primeiros treinamentos que o funcionário recebe ao se juntar a organização. Nenhuma organização apresentou uma formação profissional estruturada ou cursos específicos para o novo funcionário. $\mathrm{O}$ desenvolvimento profissional do novo funcionário ocorre enquanto realiza suas atividades, auxiliado de funcionários mais experientes. No 
caso específico de uma das OSCIPs, que desenvolve cursos e treinamentos externos, o novo funcionário poderá realizar cursos de especialização e reciclagem de seus conhecimentos, em especial sobre comércio exterior. Para os demais casos, não há especializações ou reciclagem oferecidos.

Referente ao processo de aplicar pessoas, conforme exposto por Pereira (2013) sobre a estrutura do terceiro setor, a estrutura geral das OSCIPs de Maringá também é dinâmica, considerando que os trabalhos desenvolvidos sejam, em sua maioria, projetos de curto e médio prazo. Por outro lado, o que pode-se observar na organizações estudadas é que, em praticamente todos os casos, exceto pela OSCIP que trabalha com educação política, fundada em 2016, não se observou grande rotatividade entre os funcionários ou dinamismo na estrutura. Apesar do desenho de cargos e divisão de responsabilidades não ser uma prática formalmente adotada, pode-se observar que os funcionários, devido ao tempo de trabalho, possuem uma boa interação e os processos internos já estão consolidados, o que segundo Marras (2002), pode evitar conflitos e desenvolver um clima favorável de trabalho.

De maneira geral, as organizações analisadas não apresentam uma avaliação de desempenho, seja uma avaliação formal pelo superior direto ou colegas de trabalho, ou até mesmo uma autoavaliação pelo trabalhador. Por fim, referente ao processo e higiene e segurança, em nenhum dos casos analisados há a correção de etapas de processos, considerando as medidas técnicas, educacionais e psicológicas descritas por Marras (2002). Deve-se considerar, também, o trabalho realizado nas organizações não apresentam riscos eminentes aos funcionários e dispõem de uma estrutura confortável de trabalho.

\subsection{Motivação dos funcionários}

Contou-se com a participação de quinze funcionários remunerados que trabalham integralmente entre as cinco organizações pesquisadas. Com isso, analisou-se quais as principais motivações de trabalho desses funcionários e como essas motivações são estimuladas pelas organizações, com base nas teorias de Maslow, Herzberg e McClelland.

Inicialmente, 12 dos funcionários entrevistados consideram que as OSCIPs em que trabalham apresentam uma gestão de pessoas adequada e não veem necessidades de mudanças no modelo de gestão ou em como a organização se relaciona com o funcionário. Essa constatação diverge das afirmações de Oliveira Junior (2007) e Tenório (2009) de que a priorização do público alvo da ONG em relação ao funcionário pode ocasionar desmotivação ao trabalhador, uma vez que nas organizações analisadas essa satisfação não está evidenciada. Ademais, cinco dos entrevistados trabalham há mais de seis anos na organização, chegando até 27 anos de trabalho na mesma instituição. As possíveis modificações descritas 
pelos demais indicam que, dentre as mudanças de gestão que devam ser feitas, encontram-se: feedbacks, melhoria de salário, capacitação de funcionários e investimento na estrutura da organização.

Quando questionado qual a principal motivação dos funcionários para trabalharem na OSCIP, dez entrevistados elegeram amor pela organização ou por acreditar na causa em que trabalham. Apenas dois entrevistados consideram questões financeiras como principal motivador do trabalho. Os demais buscam o crescimento profissional oferecido na organização.

Dez entrevistados consideram um papel importante da organização gerar estabilidade profissional e pessoal para os funcionários, e assumiram estarem parcialmente ou totalmente satisfeitos com este quesito. Todos os funcionários concordam que possuem boas relações de trabalho, considerando relacionamentos com funcionários, gestores e usuários que utilizam o serviço prestado pela OSCIP. Também foi unânime que consideram muito importante que a organização possibilite esse bom relacionamento.

Apenas um entrevistado acredita não ser reconhecido pelo trabalho que realiza e não consideram o reconhecimento como uma atividade importante de ser realizada pela ONG. Apesar da grande maioria de funcionários considerarem seu trabalho reconhecido, somente cinco entrevistados concordam totalmente que recebem acompanhamento sobre o desempenho, ainda que todos os candidatos vejam importância de que esse acompanhamento ocorra.

Embora as OSCIPs de Maringá apresentem uma estrutura enxuta e pouca variação de cargos, os funcionários acreditam que a organização possibilita crescimento profissional. De igual forma, nove entrevistados demonstram-se razoavelmente satisfeitos com o desenvolvimento proporcionado pela ONG por meio de treinamentos, cursos e especializações, apesar dos mesmos não terem sido identificados no questionário com o gestor. Todos os funcionários alegaram possuir autonomia para desempenhar suas tarefas diárias e apenas quatro entrevistados desejam assumir novas responsabilidades, além das que já possuem. Apesar desse valor, dez entrevistados gostariam de realizar tarefas mais desafiadoras

Quanto a relações de poder, doze entrevistados estão satisfeitos com o nível de controle que possuem sobre as atividades, enquanto apenas três afirmaram que gostariam de ter mais influência sob outras pessoas para exercer as atividades diárias. Parte desse baixo índice, diferente do esperado, deve-se ao fato que as OSCIPs de Maringá possuem recursos próprios através do serviço prestado, de maneira que não dependem de recursos governamentais ou empresariais, segundo informações obtidas na entrevista com os gestores.

Considerando as necessidades descritas por Maslow (1943), destaca-se que os funcionários, unanimemente, se sentem estáveis trabalhando para OS- 
CIPs em Maringá, satisfazendo suas necessidades fisiológicas e de segurança. Da mesma forma, todos os funcionários descrevem a interação social como uma característica essencial para o trabalho. Inclusive, a maioria ressalta esse como o principal fator motivador para seu trabalho. As necessidades de estima e realização também foram apontadas como fatores importantes.

Dentre os fatores de Herzberg (1974), pode-se analisar uma boa tolerância dos funcionários em relação aos fatores de higiene, ou fatores extrínsecos. Questões relativas à supervisão, políticas de administração, condições de trabalho e salário, para os entrevistados destacados, assumem um segundo plano. Isso é explicado pela forte motivação com a causa social desenvolvida pela ONG e envolvimento emocional com a organização, descrito como um fator motivacional. Outros fatores motivacionais como acompanhamento, crescimento profissional no que diz respeito a carreira, atribuição de novas responsabilidades e autonomia também se confirmaram importantes. É possível observar, como descrito por Morin, Tonelli e Pliopas (2007), que os trabalhadores respondentes podem sofrer menos desmotivação com as adversidades do trabalho a qual não controlam, uma vez que são motivados pela realização de um trabalho com significado para aquele que o faz.

Quanto as motivações de McClelland, devido principalmente ao caráter social e estrutura organizacional das OSCIPs, nota-se que os funcionários são motivados por orientações sociais. As relações de poder aparecem minimizadas, parte pelo fato de que as decisões não são centralizadas, parte porque os funcionários não demonstram ter suas motivações ligadas a situações em que existe influencia ou poder.

\subsection{A influência das práticas de gestão de pessoas sobre a motivação}

O funcionário, ao trabalhar no terceiro setor, confronta características específicas de trabalho, que são expostas por Oliveira Junior (2007) como flexibilidade nas tarefas, forte motivação ideológica, autonomia e foco principal nos usuários finais da $\mathrm{ONG}$, muitas vezes, deixando o trabalhador em uma posição secundária. Para a realidade de Maringá, porém, observa-se, pelas análises, que as organizações possuem características muitas vezes próximas de empresas de mercado. Pode-se considerar como um dos fatores responsáveis por essa realidade a autonomia econômica dessas instituições por meio dos serviços oferecidos, exigindo um nível de profissionalismo comparável a uma empresa de mercado. A Associação Comercial e Empresarial de Maringá também se demonstrou como uma maneira de profissionalizar os serviços oferecidos, principalmente para as OSCIPs com sede dentro das dependências da Associação Comercial, contando também com auxílio de um departamento de gestão de pessoas e assistência jurídica. 
Relacionando os cinco processos de gestão de pessoas analisados nas organizações e a motivação dos funcionários, pode-se destacar primeiramente o processo de seleção. Sempre que uma vaga é aberta, busca-se preenche-la internamente, caso seja de interesse de algum colaborador. Com isso, a organização não só possibilita o crescimento profissional dos seus funcionários, como também mantem pessoas que tenham o interesse na causa social em que a ONG atua. Caso a organização necessite de uma nova contratação, prioriza-se pessoas que já tenham contato com os atuais funcionários e conheçam sobre o funcionamento da organização, uma vez que a principal motivação dos funcionários analisada está relacionada a boa relação social, pode-se considerar que o processo de seleção é de extrema importância para a motivação da ONG como um todo. Com isso, deve-se também levar em consideração o tamanho reduzido das organizações de Maringá e a baixa rotatividade de funcionários.

O processo de recompensar pessoas não foi identificado como um importante fator motivador. Recompensas como feedbacks e reconhecimento pelo trabalho foram citados por alguns entrevistados, apesar de não haver uma avaliação formal que acompanha o desempenho do funcionário. Pode-se considerar neste caso, como já destacado no presente artigo, a hipótese de Morin, Tonelli e Pliopas (2007) que os funcionários aceitam melhor as condições de trabalho por considerarem significativo o trabalho. O mesmo se aplica ao fato que os funcionários analisados estão satisfeitos com o crescimento profissional possibilitado pela OSCIP, embora pela estrutura enxuta, as possibilidades de crescimento de cargo se tornam limitados.

Pode-se entender que o funcionário busca o crescimento profissional além do status do cargo, aumento da remuneração ou atribuição de novas responsabilidades. Confirmado pela teoria de Herzberg (1974) e Robbins (2005), o salário em si não é capaz de motivar o funcionário de uma OSCIP em Maringá, ainda que a sua ausência levaria a insatisfação. A própria política de OSCIPs, devido a não divisão de lucros, inviabiliza uma remuneração variável, o que poderia gerar motivação por recompensa.

Quanto ao processo de desenvolver pessoas, observou-se que não há um processo estruturado para isso em praticamente nenhuma das OSCIPs estudadas. Considerando que o crescimento profissional por meio de mudança de carreiras não é uma realidade dessas organizações, o desenvolvimento por meio de treinamentos, cursos e especializações pode ser uma boa alternativa para motivar o funcionário. Apesar de não ter sido identificado como um fator desmotivador para os funcionários, o desenvolvimento está ligado a fatores capazes de gerar motivação, assim como descrito por Herzberg (1974), e cabe à organização possibilitar que esse desenvolvimento ocorra.

O processo de aplicar pessoas também se apresenta em um baixo nível 
de formalidade, considerando os processos de desenho de cargos, atribuição de responsabilidade e avaliação de desempenho. Esses processos são fatores motivacionais de Herzberg (1974) e podem ser explorados pela organização.

Promover higiene e segurança, caracterizadas por necessidades básicas do trabalhador, foram vistas como satisfatórias pelos entrevistados, ainda que nenhuma organização apresente um processo específico para atuar nas correções de etapas, desenvolver estudos e implementar ações para garantir a salubridade e segurança física e mental do trabalhador.

De maneira geral, pode-se observar processos pouco desenvolvidos no setor em termos de práticas de gestão de pessoas. Os processos da área são estruturados informalmente e as atividades são realizadas de maneira reativa, ou seja, como forma de resposta às situações vivenciadas pela organização, implicando em falta de planejamento estratégico do departamento de gestão de pessoas e comprometendo o desempenho dos funcionários, uma vez que a organização busca apenas saciar as necessidades evidentes dos funcionários.

\section{CONSIDERAÇÕES FINAIS}

O objetivo do presente estudo foi compreender a influência da gestão de recursos humanos sobre a motivação no trabalho realizado por colaboradores em OSCIPs de Maringá. A relevância prática da pesquisa é fomentar a discussão desse tema pouco estudado, bem como identificar as motivações específicas de trabalhadores no terceiro setor. Ainda, buscou-se compreender como as práticas de gestão podem auxiliar em melhores condições de trabalho para o funcionário e melhor desempenho para a empresa.

A fim de atingir o objetivo proposto, descreveram-se as práticas de gestão empregadas pelos gestores no tratamento dos trabalhadores das OSCIPs estudadas. Essas organizações apresentam processos de gestão pouco estruturados e informais. No processo de atração e seleção, prioriza-se o funcionário da instituição. Em um segundo momento, buscam-se pessoas que já tenham conhecimento sobre a causa ou que sejam conhecidas dos próprios funcionários para suprirem eventuais vagas. Já o processo de recompensa, de forma geral, acontece por meio de benefícios legais exigidos pela CLT. O processo de desenvolvimento dos funcionários é feito de maneira simples e realizado apenas quando se identifica a necessidade de algum conhecimento específico para se trabalhar. Quando um novo trabalhador entra na instituição, ele será treinado por funcionários mais antigos. O processo de aplicação de pessoas é realizado de maneira informal. Por fim, promover higiene e segurança também não é um processo constante nas OSCIPs de Maringá.

Posteriormente, evidenciou-se como se apresenta a motivação desses 
trabalhadores, considerando as necessidades básicas de cada indivíduo, fatores de higiene e motivacionais e incentivos de motivação por interação social. A principal forma de motivação encontrada está relacionada aos fatores sociais. As necessidades mais básicas, como segurança e estabilidade foram identificadas como satisfatórias. Já as necessidades mais complexas de realização pessoal e estima não se destacaram como um fator motivador desses trabalhadores. Outro fato que pode ser observado é que os funcionários das OSCIPs aceitam bem as condições de trabalho as quais são submetidos, devido a sua forte motivação com a causa social e amor pela organização.

Por fim, identificou-se o impacto das práticas de gestão quanto a motivação do colaborador. Os fatores de higiene são minimizados devido a motivação com a causa social mencionada e os fatores motivacionais não são explorados pela organização. A estabilidade presente nessas organizações deve-se, também, a boa relação social entre funcionários, gestores e usuários das OSCIPs, visto como um dos principais motivadores.

Durante a realização da pesquisa, observou-se dificuldade em contatar organizações que ainda apresentem a qualificação de OSCIP, muitas das quais estão presentes no site do Ministério da Justiça, e já não estão mais em funcionamento ou não mantiveram a qualificação. Observou-se, com isso, que não há nenhum mapeamento sobre as OSCIPs em funcionamento, tanto por organizações publicas ou órgãos privados. Observou-se também que há pouca articulação entre as próprias organizações, que, muitas vezes, sofrem por problemas comuns entre elas.

Ao longo do estudo, pode-se perceber a não aceitação de ONGs para a qualificação específica de OSCIP. A qualificação, em um primeiro momento, possibilita com que a organização aplique recursos específicos do governo e organizações privadas. $\mathrm{O}$ que se pode observar é que obter recursos do governo ainda é um grande de desafio para essas organizações e organizações privadas ainda não têm confiança nos trabalhos realizados no terceiro setor. Sugere-se para futuras pesquisas uma análise sobre OSCIPs que recebam repasses públicos e privados, a fim de avaliar a estratégia e especificidades para que esse repasse de verba ocorra. Pode-se, também, aprofundar a discussão quanto a qualidade de vida dos trabalhadores no terceiro setor, devido ao forte envolvimento emocional do indivíduo com o trabalho em que realiza e pela causa o qual trabalha.

\section{REFERÊNCIAS}

ALMEIDA, M. I. R. D.; TEIXEIRA, M. L. M.; MARTINELLI, D. P. Por que administrar estrategicamente recursos humanos? Revista de Administração de Empresas, v. 33, n. 2, p. 12-24, 1993. 
ASSIS, L. B.; VIEGAS, G.; CKAGNAZAROFF, I. B. Gestão de Recursos Humanos no Terceiro Setor: um estudo descritivo das organizações de Belo Horizonte. GESTÃO. Org-Revista Eletrônica de Gestão Organizacional, v. 10, n. 2, 2012.

BARROS, R. P.; FOGUEL, M.; ULYSSEA, G. Desigualdade de Renda no Brasil: uma análise da queda recente. Brasília: Ipea, 2006. 446 p.

BERGAMINI, C. W. Liderança: a administração do sentido. Revista de Administração de Empresas. v. 32, p. 102-114, 1994.

BORDALO, A. A. Estudo transversal e/ou longitudinal. Revista Paraense de Medicina, v. 20, n. 4, p. 5, 2006.

BOHLANDER, G.; SNELL, S. Administração de Recursos Humanos. 14. ed. São Paulo: Cengage Learning, 2009.

CALDANA, A. C.; SOUZA, L. B.; CAMILOTO, C. M. Sentidos das ações voluntárias: desafios e limites para a organização do trabalho. Psicologia \& Sociedade. 2012.

DINIZ, J. H. A. S.; MATTOS, P. Organizações não governamentais e gestão estratégica: desfiguração de seu caráter institucional-original. Encontro Anual da Associação Nacional dos Programas de Pós-Graduação em Administração, 2002.

FERNANDES, R. C. O que é o terceiro setor? Revista do legislativo, Belo Horizonte: Assembleia Legislativa do Estado de Minas Gerais, n. 18, p. 26-30. 1997.

FISCHER, A. L. A constituição do modelo competitivo de gestão de pessoas no Brasil: um estudo sobre as empresas consideradas exemplares. Tese (Doutorado em Administração). Universidade de São Paulo, 1998.

GODOY, A. S. Introdução à pesquisa qualitativa e suas possibilidades. Revista de administração de empresas, v. 35, n. 2, p. 57-63, 1995.

HERZBERG, F. Workers' needs: the same around the world. Industry Week, n. 243, p. 29. 1987.

LEWIS, D. The management of non-governmental development 
organizations. London, Routledge, 2001.

LIMA NETO, F. Relação com o Estado na visão das ONGs: uma sociologia das percepções. Instituto de Pesquisa Econômica Aplicada (IPEA), 2013.

MARRAS, J. P. Administração de recursos humanos: do operacional ao estratégico, v. 3, São Paulo, 2000.

MELO, M. F. ONGS e relações institucionais: primeiro, segundo e terceiro setores. Ciências Sociais Unisinos. v. 52, n. 1, p. 88-99, feb. 2016.

MASLOW, A. H. A theory of human motivation. Psychological review, 1943. $370 \mathrm{p}$.

MCCLELLAND, D. C. A Sociedade competitiva: realização e progresso social. Rio de Janeiro: Expressão Cultural, 1972. 582 p.

MCCLELLAND, D.C. Managing motivation to expand human freedom. American Psychologist. v. 33, n. 3, p. 201, 1978.

MCCLELLAND, D. C.; WATSON, R. I. Power motivation and risk $\square$ taking behavior. Journal of personality. v.41, n.1, p. 121-139, 1973.

MESSEDER, J. E. C. Em busca de um modelo integrado de planejamento e desenvolvimento de recursos humanos. Revista de Administração Pública, v. 26, n. 3, 1992.

OLIVEIRA JÚNIOR, C. A. ONG'S como espaço de investimento profissional. RECADM. v. 6, n. 2, p. 1-14, 2007.

PAULA, A. P. P. Administração pública brasileira entre o gerencialismo e a gestão social. RAE - Revista de Administração de Empresas. v. 45, n. 1. p. 36-49, 2005.

PEREIRA, M. Gestão para Organizações Não Governamentais. Florianópolis: Editora Tribo da Ilha, 2013.

PINTO, J. R. D. A. G. Gestão de Recursos Humanos: motivações e incentivos. Estudo da orientação personalizada da aptidão física dos colaboradores da" Odlo" Portugal, Tese (Mestrado em Gestão Esportiva, Porto, 2013. 
PONTES, B. R. Planejamento, recrutamento e seleção de pessoal. LTr. 2005

SILVA, R. O. Teorias da administração. São Paulo: Pearson Prentice Hall, 2008.

ROBBINS, Stephen, P. Comportamento organizacional. São Paulo: Prentice Hall, 2005.

ROESCH, S. M. A. Gestão de ONGs: rumo a uma agenda de pesquisas que contemple a sua diversidade. Encontro anual da associação nacional dos programas de pós-graduação em administração. v. 26, 2002.

SEVERINO, A. J. Metodologia do trabalho cientifico. São Paulo: Editora Cortez, 2005.

TENÓRIO, F. G. (1997). Gestão de ONGs: principais funções gerenciais. $11^{\mathrm{a}}$ edição. Rio de Janeiro: FGV editora, 2009.

TENÓRIO, F. G. A trajetória do Programa de estudos em Gestão Social (PEGS). Revista de Administração Pública, v. 40, n. 6, 2006.

TONELLI, M. J.; MORIN, E.; PLIOPAS, A. L. O Trabalho e Seus Sentidos. Revista Psicologia \& Sociedade. v. 19, 2007. 